(c) (i)

\title{
Helvella leucomelaena (Pers.) Nannf.'In antimikrobiyal ve antioksidan Etkisi
}

\section{Antimicrobial And antioxidant effect of Helvella leucomelaena (Pers.) Nannf.}

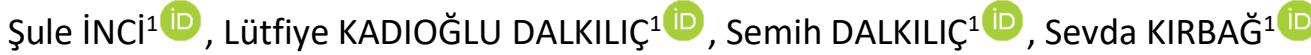 \\ ${ }^{1}$ Biyoloji Bölümü, Fen Fakültesi, Fırat Üniversitesi, TR 23119, Elazığ-Türkiye
}

\section{Eser Bilgisi / Article Info}

Araştırma makalesi / Research article

DOI: 10.17474/artvinofd.601528

Sorumlu yazar / Corresponding author Şule inci

e-mail: sule.inci@hotmail.com

Geliş tarihi / Received

05.08.2019

Düzeltme tarihi / Received in revised form 30.09.2019

Kabul Tarihi / Accepted

04.10.2019

Elektronik erişim / Online available 30.10.2019

Anahtar kelimeler:

Helvella leucomelaena

Antimikrobiyal aktivite

Antioksidan aktivite

\section{Keywords:}

Helvella leucomelaena

Antimicrobial activity

Antioxidant activity

\begin{abstract}
Özet
Mantarlar içerdikleri aktif bileşenler sayesinde besleyici bir gıda olarak tüketilmelerinin yanı sıra tıbbi ve tedavi edici özelliklerinden dolayı uzun yıllardır halk tarafından kullanılmaktadırlar. Mantarların immünolojik ve antikanser özelliklerinin yanı sıra antioksidan, antihipertensif, kolesterol düşürücü, karaciğer koruyucu, antifibriotik, antiinflamasyon, antidiyabetik, antiviral ve antimikrobiyal etkileri olduğu bilinmektedir. Yenilebilir olan mantarlardan Helvella leucomelaena (Pers.) Nannf. Ascomycota' nın Helvellaceae'ye ait bir mantar türüdür.

Bu çalışmada $H$. leucomelaena'nın metanol, etanol ve hekzan gibi çözücülerden elde edilen ekstraklarının farklı konsantrasyonları kullanılarak antimikrobiyal aktivitesinin belirlenmesi ve metanol çözücüsü kullanılarak elde edilen ekstraktının farklı konsantrasyonlarının antioksidan aktivitesinin belirlenmesi amaçlanmıştır. Antimikrobiyal aktivitesi disk difüzyon metoduna göre tespit edilmiştir. Çalışma için Staphylococcus aureus ATCC25923, Klebsiella pneumoniae ATCC700603, Escherichia coli ATCC25322 ve Bacillus megaterium DSM32 gibi bakteriler, fungus olarak Candida albicans FMC17 mikroorganizmaları kullanılmıştır. Antioksidan aktivitesi ise 2,2-difenil-1-pikrilhidrazil (DPPH) yöntemine göre radikal süpürücü kapasite tespit edilmiştir. Sonuçta $H$. leucomelaena en yüksek inhibisyon zonunu C. albicans'a karşı $(16 \mathrm{~mm}) 750 \mu \mathrm{g}$ konsantrasyonda etanol ekstresinde gösterdiği tespit edilmiştir. DPPH radikalini süpürücü etkisi ise artan konsantrasyonlara bağlı olarak arttığı gözlemlenmiştir.
\end{abstract}

\begin{abstract}
Mushrooms have been used by the public for many years due to the active containts they contain as well as being consumed as a nutritious food. It is known that mushrooms have antioxidant, antihypertensive, cholesterol-lowering, liver-protective, antifibriotic, anti-inflammation, antidiabetic, antiviral and antimicrobial effects as well as immunological and anticancer properties. From the edible mushrooms Helvella leucomelaena (Pers.) Nannf. "white-footed elf cup", belong to Helvellaceae Ascomycota's is a mushroom species.

The aim of this study was to determine the antimicrobial activity of $\mathrm{H}$. leucomelaena by using different concentrations of extracts obtained from solvents such as methanol, ethanol and hexane, and to determine the antioxidant activity of different concentrations of extract obtained using methanol solvent. Antimicrobial activity was determined by disc diffusion method. For the study, bacteria such as Staphylococcus aureus ATCC25923, Klebsiella pneumoniae ATCC700603, Escherichia coli ATCC25322 and Bacillus megaterium DSM32; Candida albicans FMC17 as fungi microorganisms were used. Antioxidant activity was determined according to 2,2-diphenyl-1-picrylhydrazyl (DPPH) radical quenching capacity method. As a result, $H$. leucomelaena showed the highest inhibition zone against C. albicans $(16 \mathrm{~mm})$ at $750 \mu \mathrm{g}$ concentration in ethanol extract. The scavenging effect of DPPH radical was observed to increase depend to increasing concentrations.
\end{abstract}

\section{GíRiş}

Mantarlar uzun yıllardır besin olarak tüketilmelerinin yanı sıra birçok hastalığın tedavisinde ilaç olarak kullanılmaktadırlar (Saldır 2015). Yapılarında önemli esansiyel aminoasitler, karbonhidratlar, lifler, bazı vitaminler ve mineraller bulunmaktadır (Öztürk ve Çopur
2009). Besleyici gıda olmalarının yanında önemli biyoaktif bileşenlere sahip tıbbi besinlerdir (Sevindik 2017; Devi ve ark. 2012). Bu bileşenler bazı mantar türlerinde antibakteriyel, antifungal, antiprotozoal ve antiviral aktiviteler gösterdiği bilinmektedir (Yıldız Turp ve Boylu 2018). Mantarların antimikrobiyal etkileri sentezledikleri 
bazı fenolik bileşikler, purinler, pirimidinler, kinonlar, terpenoitler ve fenil propanoit türevi antagonistik maddelerden kaynaklanmaktadır (Öztürk ve Çopur 2009). Antioksidan potansiyelleri ise içerdikleri fenolik bileşikler, poliketidler, terpenler ve steroidler gibi sekonder metabolitlerden kaynaklanmaktadır (Cheung ve ark. 2003; Özcan 2015).

Yenilebilir mantarlardan olan Helvella leucomelaena (Pers.) Nannf., Ascomycota' nın Helvellaceae sınıfına aittir (Kirk ve ark. 2008). Gövdesinin beyaz rengiyle karakterizedir (Tylutki 1979). Kuzey Amerika'da nadir olarak görülse de Kaliforniya, Alaska ve Rocky Dağları'nda sık görülmektedir (Orr Robert ve Dorothy 1979). Güney Amerika ve Avrupa'da da kayıtları bulunmuştur (Dissing 1966; Calonge ve Arroyo 1990). Ülkemizde de farklı lokalitelerde yetiştiği bilinmektedir (Akata ve Kaya 2012).

Bu çalışmada Helvella leucomelaena (Pers.) Nannf.' ın metanol, etanol ve hekzan gibi çözücülerden elde edilen ekstraktlarının farklı konsantrasyonları kullanılarak antimikrobiyal aktivitesi ve metanolden elde edilen ekstraktının ise farklı konsantrasyonlarının antioksidan aktivitesinin belirlenmesi amaçlanmıştır.

\section{MATERYAL VE YÖNTEM}

\section{Antimikrobiyal Aktivitenin Belirlenmesi Test Mikroorganizmaları}

Bu çalışmada; Staphylococcus aureus ATCC 25923, Klebsiella pneumoniae ATCC 700603 Escherichia coli ATCC 25322 ve Bacillus megaterium DSM32 gibi bakteriler, fungus olarak Candida albicans FMC17 kullanılmıştır. Mikroorganizma kültürleri Fırat Üniversitesi, Fen Fakültesi, Biyoloji Bölümü, Mikrobiyoloji Laboratuvarı kültür koleksiyonundan sağlanmıştır.

\section{Materyalin Toplanması ve Teşhisi}

Helvella leucomelaena Elazığ'ın Sivrice ilçesinde 2017 Nisan ayında toplanmıştır. Makroskobik ve mikroskobik çalışmalar yapılarak türün teşhisi yapılmıştır (Asef 2014).

\section{Materyalin Elde Edilmesi ve Hazırlanışı}

$H$. leucomelaena kurutulup, değirmende toz haline getirildikten sonra 50 gr alınarak 100 ml \%96'lık metanol, etanol ve hekzan solventleri kullanılarak soxhlet cihazında
7 saat süreyle özüt eldesi gerçekleştirilmiştir. Daha sonra rotary evaporator kullanılarak özütlerin içinde kalan alkol $40{ }^{\circ} C^{\prime}$ de yoğunlaştırılmıştır Liyofilize edilerek tamamen kurutulan droglar analiz edilene kadar $+4{ }^{\circ} \mathrm{C}^{\prime}$ de saklanmıştır.

\section{Mikroorganizma Kültürlerinin Hazırlanması ve Antimikrobiyal Etkinin Test Edilmesi}

$H$. leucomelaena'nın metanol, etanol ve hekzan ekstraklarının antimikrobiyal aktivitesi disk diffüzyon metoduna göre tespit edilmiştir (Collins ve Lyne 1987). Bakteri suşları (Staphylococcus aureus ATCC25923, Klebsiella pneumoniae ATCC700603 Escherichia coli ATCC25322 ve Bacillus megaterium DSM32), nutrient buyyon'a (Difco) aşılanarak $35 \pm 1^{\circ} \mathrm{C}^{\prime}$ de 24 saat, maya suşu (Candida albicans FMC17) malt ekstrakt buyyon'da (Difco) $25 \pm 1^{\circ} \mathrm{C}^{\prime}$ de 48 saat süre ile inkübe edilmiştir. Hazırlanan bakteri ve mayanın buyyon'daki kültürü sırasıyla; Müeller Hinton Agar ve Sabouraud Dextrose Agar içine \% 1 oranında aşılanarak $\left(10^{6}\right.$ bakteri/ml, $10^{4}$ maya/ml) iyice çalkalandıktan sonra $9 \mathrm{~cm}$ çapındaki steril petri kutularına $25 \mathrm{ml}$ konularak besiyerinin homojen bir şekilde dağılması sağlanmıştır. Katılaşan agar ortamına aseptik olarak her biri farklı konsantrasyonlarda (250, 500, $750 \mu \mathrm{g} /$ disk) ekstraktlar emdirilmiş olan $6 \mathrm{~mm}$ çapındaki antimikrobiyal diskler (Oxoid) hafifçe yerleştirilmiştir. Bu şekilde hazırlanan petri kutuları $4^{\circ} \mathrm{C}$ 'de 1.5-2 saat bekletildikten sonra, bakteri aşılanan plaklar $37 \pm 0.1^{\circ} \mathrm{C}^{\prime}$ de 24 saat, maya aşılanan plak ise $25 \pm 0.1^{\circ} \mathrm{C}^{\prime}$ de 72 saat süre ile inkübe edilmiştir. Kontrol için standart diskler kullanılmıştır (Amoksisilin 30 Mg/disk, Klindamisin $2 \mu \mathrm{g} /$ disk). Negatif kontrol için dimetil sülfoksit (DMSO) kullanılmıştır. Süre sonunda besiyeri üzerinde oluşan inhibisyon zonları $\mathrm{mm}$ olarak değerlendirilmiştir.

\section{Antioksidan Aktivitenin Belirlenmesi}

$H$. leucomelaena'nın metanol ekstresinin farklı konsantrasyonlarının antioksidan aktivitesi ise 2,2-difenil1-pikrilhidrazil (DPPH) radikal süpürücü kapasitesi yöntemine göre belirlenmiştir (Cuendet ve ark. 1997; Kirby ve Scmidt 1997). Liyofilize ile elde edilmiş drogdan 5 $\mathrm{mg} / \mathrm{ml}$ konsantrasyonda çözelti metanolde hazırlanmıştır. Hazırlanan çözelti üç kez dilüe edilerek DPPH'ın kalibrasyon eğrisi çıkarılmıştır. Hazırlanan çözeltiden $40 \mu \mathrm{l}$ 
alınarak üzerine $160 \mu \mathrm{l}$ DPPH çözeltisi ilave edilmiştir. Kuvvetlice karıştırılıp ağzı kapatıldıktan sonra $30 \mathrm{dk}$. süre ile karanlıkta bekletilmiştir. Tüm konsantrasyonlar için aynı işlemler tekrarlanmış ve kontrol olarak metanol kullanılmıştır. Bu sürenin sonunda her bir karışımın absorbansları spektrofotometrede $517 \quad \mathrm{~nm}$ 'de okunmuştur. \% inhibisyon değerleri hesaplanmıştır;

\section{BULGULAR ve TARTIŞMA}

H.leucomelaena'nın farklı çözücüler ve konsantrasyonlardaki antimikrobiyal sonuçları Çizelge 1 'de verilmiştir.

$I(\%)=(A 0-$ Anumune $/ \mathrm{AO}) \times 100$

Çizelge 1: Helvella leucomelaena'nın antimikrobiyal etkisi

\begin{tabular}{|c|c|c|c|c|c|}
\hline & \multicolumn{4}{|c|}{ İnhibisyon zonları (mm) } & \multirow[b]{2}{*}{ C. albicans } \\
\hline & E. coli & S.aureus & K. penumoniae & B. megaterium & \\
\hline H-hekzan $(250 \mu \mathrm{g})$ & - & - & 8 & - & 9 \\
\hline H-hekzan $(500 \mu \mathrm{g})$ & - & - & 8 & - & 12 \\
\hline H-hekzan $(750 \mu \mathrm{g})$ & - & - & 9 & - & 14 \\
\hline H-metanol $(250 \mu \mathrm{g})$ & - & 8 & 9 & 7 & - \\
\hline 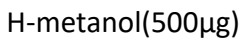 & - & 9 & 11 & 7 & - \\
\hline 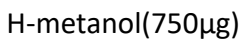 & - & 9 & 13 & 9 & - \\
\hline H-etanol $(250 \mu \mathrm{g})$ & - & 7 & - & 7 & 9 \\
\hline H-etanol $(500 \mu \mathrm{g})$ & - & 8 & - & 8 & 12 \\
\hline H-etanol(750 $\mu \mathrm{g})$ & - & 11 & - & 9 & 16 \\
\hline Amoksisilin & 11 & 11 & 15 & 14 & 7 \\
\hline Klindamisin & 21 & 26 & 20 & 17 & 9 \\
\hline DMSO & - & - & - & - & - \\
\hline
\end{tabular}

H. leucomelaena'nın hekzan ekstresi E. coli, S. aureus ve $B$. megaterium'un gelişimini engellemediği, $K$. pneumoniae ve $C$. albicans'ın gelişimini tüm konsantrasyonlarda engellediği tespit edilmiştir. $H$. leucomelaena'nın metanol ekstresi $E$. coli ve $C$. albicans'a karşı aktivite göstermezken $S$. aureus, (8-9mm), B. megaterium, (7-9 mm) ve $K$. pneumaniae'ye karşı artan konsantrasyona bağlı olarak inhibisyon etkisinin arttığı belirlenmiştir ( 9, 11, $13 \mathrm{~mm}$ inhibisyon zonu). $H$. leucomelaena'nın etanol ekstresi $S$. aureus, $B$. megaterium ve $C$. albicans'a karşı ise artan konsantrasyona bağı ılarak inhibisyon zonunun arttığı belirlenmiştir. E.coli ve $K$. pneumoniae'nin gelişimini engellememiştir (Çizelge 1 ). Bu çalışmada $H$. leucomelaena en yüksek inhibisyon zonunu C. albicans'a karşı $(16 \mathrm{~mm}) 750 \mu \mathrm{g} /$ disk konsantrasyonda etanol ekstresinde gösterdiği tespit edilmiştir. Standart olarak kullanılan Klindamisin diğer standart antibiyotiğe ve kullanılan mantar özütlerine göre mikroorganizmaların gelişimini daha fazla engellediği tespit edilmiştir.
Aynı mantarın aseton, etil asetat, etil alkol ve kloroform gibi çözücüler kullanılarak elde edilen ekstraklarının E.coli'ye karşı inhibisyon zonu oluşturmadığı, aseton ve etil asetat ekstrelerinin $S$. aureus'a karşı $8 \mathrm{~mm}$ ve en yüksek inhibisyon zonunun kloroform ekstresinde $P$. aureginosa'ya karşı $(14 \mathrm{~mm})$ olduğu rapor edilmiştir (Demirhan ve ark. 2007). Helvella leucopus'un metanol ekstraktının E. coli $(11 \mathrm{~mm})$, S. aureus $(9 \mathrm{~mm})$, B. subtilis $(5 \mathrm{~mm})$ M. luteus $(6 \mathrm{~mm})$ gelişimlerini inhibe ettiği $P$. aeruginosa'ya karşı etki göstermediği belirlenmiştir (Dündar ve ark. 2015). Helvella crispa'dan elde edilen protocatekhuik asit, gallik asit ve vanilik asidin mikroorganizmaların gelişimlerini engellediği tespit edilmiştir (Alves ve ark. 2013). Helvella lacunosa ekstraktının B. subtilis ve $C$. albicans'a etki etmediği, $E$. coli'nin ise gelişimini engellediği belirlenmiştir (Maillard ve ark. 2002). Helvella lacunosa'nın diklorometan ekstresi B. subtilis ve $C$. albicans'ın gelişimini engellemezken $E$. coli'nin gelişimini inhibe ettiği bildirilmiştir (Keller ve ark. 2002). 
H. leucomelaena'nın $5 \mathrm{mg} / \mathrm{ml}$ konsantrasyonunda DPPH radikalinin inhibisyon yüzdesi 4 farklı konsantrasyon için \%20-1 arasında bulunmuştur (Çizelge 2).

Çizelge 2: Helvella leucomelaena'nın DPPH radikalinin inhibisyon yüzdesi

\begin{tabular}{lc}
\hline Konsantrasyon & DPPH radikalinin \% inhibisyonu \\
\hline $\mathbf{5 ~ m g / m l}$ & 20 \\
$\mathbf{2 . 5} \mathrm{mg} / \mathrm{ml}$ & 8 \\
$\mathbf{1 . 2 5} \mathrm{mg} / \mathrm{ml}$ & 4 \\
$0.625 \mathrm{mg} / \mathrm{ml}$ & 1 \\
\hline
\end{tabular}

H. leucomelaena'nın DPPH radikalini süpürücü etkisi artan konsantrasyonlara bağlı olarak arttığı gözlemlenmiştir. $H$. leucomelaena'nın daha önceki yapılan antioksidan çalışmasında total antioksidan seviyesinin (TAS) 2.367 $\mathrm{mmol} / \mathrm{L}$, total oksidan seviyesinin (TOS) $55.346 \mu \mathrm{mol} / \mathrm{L}$ olduğu saptanmış ve yüksek antioksidan değerine sahip olduğu rapor edilmiştir (Sevindik ve ark. 2008). Helvella crispa'nın antioksidan aktivitesinin \%10.24, Peziza cerea'nın \%52.55 ve Peziza vesiculosa'nın ise \%40.99 olduğu tespit edilmiştir (Macáková 2011). Helvella crispa'nın 100, 200, 300, 400, 500 ve $600 \mu \mathrm{g} / \mathrm{ml}$ konsantrasyonlarda sırasıyla antioksidan aktivitelerinin $\% 9.0, \% 12.21, \% 20.48, \% 33.25, \% 53.90$ ve $\% 55.55$ olduğu saptanmıştır (Pala ve Wani 2011).

H. leucopus'un $20 \mathrm{mg} / \mathrm{mL}$ konsantarsyonda DPPH süpürücü aktivitesinin $\% 92.42$ ve $H$. queletii'nin ise \%87.65 olduğu yapılan çalışmalarda rapor edilmiştir (Dundar ve ark. 2015). Helvella lacunosa'nın diklorometan ekstresinin DDPH aktivitesinin olmadığı tespit edilmiştir (Keller ve ark. 2002). Aynı türün etil asetat ekstarktında DPPH aktivitesinin $(200 \mu \mathrm{g} / \mathrm{mg}) \% 55$ \pm 4.19 (Shameem ve ark. 2016), metanol ekstraktında ise $26.92 \pm 1.37$ (EC50; $\mathrm{mg} / \mathrm{mL}$ ) olduğu tespit edilmiştir (Leal ve ark. 2013).

Yapılan bu çalışmanın sonuçları ile diğer çalışma sonuçları arasında benzerlik veya farklılıklar olduğu tespit edilmiştir. Bunun nedeni mantarın toplandığı habitatların ayrı olması ve aynı genusa ait türlerin kimyasal içeriklerinin farklı olmasından kaynaklanabilir.

Sonuçlara göre $H$. leucomelaena'nın antioksidan ve antimikrobiyal etkilerinin olduğu tespit edilmiştir. Bu türün doğal bir antimikrobiyal ve antioksidan ajan olabileceği önerilebilir. H. leucomelaena 'nın tıbbi ve tedavi edici özelliklerinin daha fazla araştırılması gerektiğini düşünmekteyiz.

\section{KAYNAKLAR}

Akata I, Kaya A (2012) Two New Helvella Records For Turkish Mycobiota. Journal of Applied Biological Sciences 6 (3): 31-33.

Alves MJ, Ferreira ICFR, Froufe HJC, Abreu RMV, Martins A, Pintado M (2013) Antimicrobial activity of phenolic compounds identifiedin wild mushrooms, SAR analysis and docking studies. Journal of Applied Microbiology 115: 346-357.

Asef MR (2014) The genus Helvella in Iran. Mycologia Iranica 1(1): 13 -18 .

Calonge FD, Arroyo I (1990) Notes on the genus Helvella in Spain. Mycotaxon 39: 203-17

Cheung LM, Cheung PCK, Ooi VEC (2003) Antioxidant activity and total phenolics of edible mushroom extracts. Food Chemistry 81 : 249-255.

Collins CM, Lyne PM (1987) Microbiological methods. Butterworths \& Co. Ltd., London.

Cuendet M, Hostettmann K, Potterat O, Dyatmiko W (1997) Iridoid glucosides with free radical scavenging properties from Fagraea blumei. Helvetica Chimica Acta 80(4): 1144-1152

Demirhan A, Yeşil ÖF, Yıldız A, Gül K (2007) Bazı Makrofungus Türlerinin Antimikrobiyal Aktiviteleri Üzerine Bir Araştırma. Firat Üniversitesi Fen Ve Mühendislik Bilimleri Dergisi 19(4): 425-433.

Devi P, Rodrigues C, Naik CG, D'Souza L (2012) Isolation and characterization of antibacterial compound from a mangroveendophytic fungus, Penicillium chrysogenum MTCC 5108. Indian J Microbiol 52(4): 617-623.

Dissing $H$ (1966) The genus Helvella in Europe with special emphasis on the species found in Norden. Dansk Botanisk Arkiv 25: 1-172.

Dundar A, Okumus V, Ozdemir S, Celik KS, Boga M, Ozcagli E, Ozhan G, Yildiz A (2015) Antioxidant, Antimicrobial, Cytotoxic and Anticholinesterase Activities of Seven Mushroom Species with their Phenolic Acid Composition. J Horticulture 2: 161.

Keller C, Maillard M, Keller J, Hostettmann K (2002) Screening of European Fungi for Antibacterial, Antifungal, Larvicidal, Molluscicidal, Antioxidant and Free-Radical Scavenging Activities and Subsequent Isolation of Bioactive Compounds. Pharmaceutical Biology 40 (7): 518-525

Kirby AJ, Schmidt RJ (1997) The antioxidant activity of Chinese herbs for eczema and of placebo herbs. I. Journal of Ethnopharmacology 56(2): 103-8.

Kirk PF, Cannon PF, Minter DW, Stalpers JA (2008) Dictionary of the fungi. 10th ed. CAB International. Wallingford, UK.

Leal AR, Barrosa L, Barreiraa JCM, Sousa MJ, Martins A, SantosBuelga C, Ferreira ICFR (2013) Portuguese wild mushrooms at the"pharma-nutrition"interface: Nutritional characterization and antioxidant properties. 50: 1-9.

Macáková K (2011) Biological Activity of Selected Taxons of Mushrooms From Divisions Ascomycota And Basidiomycota. Charles University Faculty of Pharmacy Doctoral Dissertation, Prague, 114 s.

Orr Robert T, Dorothy B (1979) Mushrooms of Western North America. University of California Press: Bereley, CA. 293p.

Özcan Ö (2015) Trakya Bölgesindeki Bazı Yenebilen Mantar Türlerinin Beta-Glukan İçeriklerinin, Antioksidan Ve Antimikrobiyal Aktivitelerinin Kültür Mantarı İle Karşılaştırılması. Trakya Üniversitesi Fen Bilimleri Enstitüsü Doktora Tezi, Edirne, 96s.

Öztürk A, Çopur ÖU (2009) Mantar Bileşenlerinin Teröpatik Etkileri. Bahçe 38 (1): 19-24. 
Pala SA, Wani AH (2011) Antioxidant activity of some wild mushrooms of Kashmir Valley. Bioresearch Bulletin 2: 125-129.

Saldır Y (2015) Bazı mantarların antimikrobiyal ve antioksidan özelliklerinin araştırılması. Pamukkale Üniversitesi Fen Bilimleri Enstitüsü Yüksek Lisans Tezi, Denizli, 48 s.

Sevindik M (2017) Mushrooms as Natural Antioxidant Agents. J Tradit Med Clin Natur. 6:239.

Sevindik M, Akgul H, Korkmaz Aİ, Sen İ (2018) Antioxidant potantials of Helvella leucomelaena and Sarcosphaera coronaria. Journal of Bacteriology \& Mycology, 6(1).

Shameem N, Kamili AN, Ahmad M, Masoodi FA, Parray JA (2016) Antioxidant Potential and DNA Damage Protection by the Slate Grey Saddle Mushroom, Helvella lacunosa (Ascomycetes), from Kashmir Himalaya (India). Int J Med Mushrooms. 18(7):631-6.

Tylutki EE (1979) Mushrooms of Idaho and the Pacific Northwest. Moscow: University Press of Idaho.

Yildız Turp G, Boylu M (2018) Tibbi ve Yenilebilir Mantarlar ve Et Ürünlerinde Kullanımı. YYÜ Tar Bil Derg. 28(1): 144-153. 